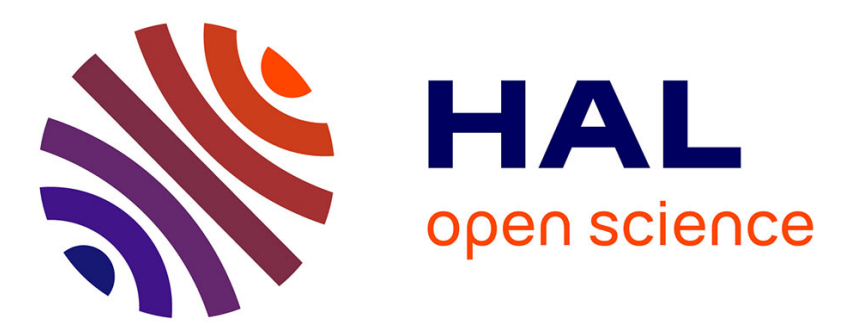

\title{
Magnetic Flux Density Measurement in Permanent Magnet Synchronous Machines
}

\author{
A Saadoun, Yassine Amirat
}

\section{To cite this version:}

A Saadoun, Yassine Amirat. Magnetic Flux Density Measurement in Permanent Magnet Synchronous Machines. 15th international conference on Sciences and Techniques of Automatic control \& computer engineering - STA'2014, Dec 2014, Hammamet, Tunisia. hal-01122624

\section{HAL Id: hal-01122624 \\ https://hal.science/hal-01122624}

Submitted on 4 Mar 2015

HAL is a multi-disciplinary open access archive for the deposit and dissemination of scientific research documents, whether they are published or not. The documents may come from teaching and research institutions in France or abroad, or from public or private research centers.
L'archive ouverte pluridisciplinaire HAL, est destinée au dépôt et à la diffusion de documents scientifiques de niveau recherche, publiés ou non, émanant des établissements d'enseignement et de recherche français ou étrangers, des laboratoires publics ou privés. 


\title{
Magnetic Flux Density Measurement in Permanent Magnet Synchronous Machines
}

\author{
A. Saadoun and Y. Amirat, Member, IEEE
}

\begin{abstract}
This paper describes two measurement techniques of the air gap flux density in a small permanent magnet synchronous machine. The first method is based of the harmonic analysis of the induced voltage in a search coil placed on the inner periphery of the stator, while the second relies on the analysis of the induced voltage in the stator windings. Accurate results can be achieved since the measurement procedure relies only on well defined electrical quantities regardless of the dimensions of the machine. A further appreciation of the accuracy of the proposed measurement procedures can be confirmed by the reconstruction of the stator induced voltages. Although each method has its own merit in terms of field sensing, they are basically identical; nonetheless they enable a cross comparison of the measured results.
\end{abstract}

Keywords — Poisson's equation for magnetic field problems; finite element modeling; induced emf

\section{INTRODUCTION}

The computation of the air gap flux density in electric machines is certainly the most important aspect of the design procedure. Despite the long experience accumulated by several generations of electric machines designers, the task is still a state of art [1]. It has become even more challenging as far as permanent machines are concerned because the air gap field distribution is difficult to predict by the classic methods [2]. To overcome the problem, finite element software packages are presently used to solve directly the governing magnetic field equation. However, the final assessment of the finite element solution can be only made on the basis of the experimental results. The present work has been carried out, initially, in the prospect to validate the finite element model of the machine, but during the course of the experiments, not only great discrepancies between the computed and measured results have been found but also unexpected field harmonics caused by mechanical asymmetry between two adjacent pair pole pitches have been observed. Since in permanent magnet machines, the air gap is made comparatively shorter in order to optimise the dimensions of the magnet, it has turned out that the calculation of the air gap flux density is very sensitive to the dimensions of the machine, particularly on the location of the mean air gap line $[3,4]$. To alleviate the impact of the machine dimensions on the calculation of the radial component of the air gap field, two methods have been used to check the consistency of the measurements. The first method relies on the harmonic analysis of the induced emf in a search coil whereas the second is based on the analysis of the induced emf in the stator windings. However, the calculation of the air gap flux density harmonics still depends on the dimension of the machine; therefore another formulation is needed to get rid off these parameters from the measurement procedures.

\section{FEM MODELLING OF THE PMSM}

The Poisson's equation governing the magnetic field problem

$$
\frac{\partial}{\partial x}\left(v_{y} \frac{\partial A}{\partial x}\right)+\frac{\partial}{\partial y}\left(v_{x} \frac{\partial A}{\partial y}\right)=-J_{\Sigma}
$$

has been solved over a domain solution restricted to one pole pitch, using the freeware FEM package FEMM v4. The two dimensional finite element model of the permanent machine is shown in figure 1. Figure 2 represents the magnetic air gap Flux Density Distribution (FDD) along the mid-air gap line.

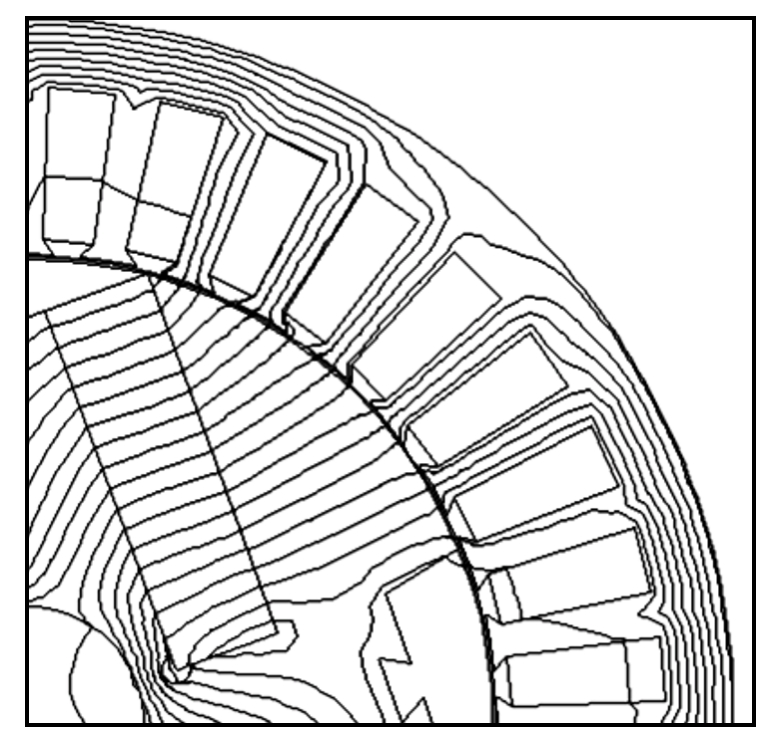

Figure 1: Flux line contours from the FEMM package fem solution over a pole pitch. 


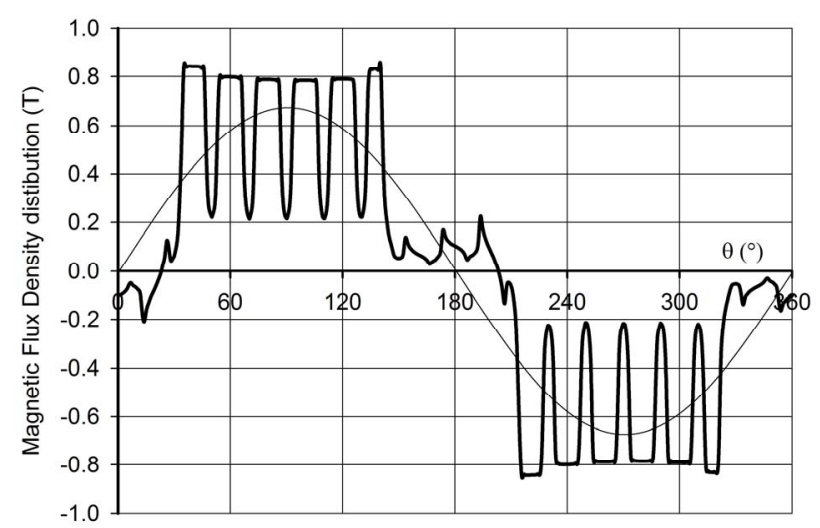

Figure 2: Computed magnetic flux density distribution along the mid-air line.

\section{MEASUREMENT PROCEDURE}

The key point of the measurement procedure is to derive a relationship between the induced voltage and the radial component of the flux density distribution in which the dimensions of the machine are not expressed explicitly. The induced voltage within a particular conductor of the winding is derived from the "flux-cutting" rule as

$$
e_{c}(t)=B(\theta) l v
$$

where $B(\theta)$ represents the air gap FDD along the mean air gap line. Provided that the peripheral speed of the rotor $v$ is constant the induced emf $e_{c}(t)$ signal, shown in figure 2, represents also the waveform of the air gap field which can be described by a Fourier series

$$
B(\theta)=\sum_{k=1}^{N} B_{m k} \sin \left(k \theta+\varphi_{k}\right)
$$

The r.m.s value of the induced signal due to the fundamental is

$$
E_{c 1}=\sqrt{\frac{2}{T} \int_{0}^{\frac{2}{T}} e_{c 1}^{2} d t}=l v \sqrt{\frac{2}{T} \int_{0}^{\frac{2}{T}} B_{m 1}^{2} d t}=l v B_{1}
$$

This relation is manipulated by expressing the peripheral speed

$$
v=\pi D n=2 \tau f
$$

in terms of the pole pitch $\tau$ and the frequency of the induced emf voltage due to the rms value $B_{1}$ of the fundamental of the air gap field. Furthermore, the average flux per pole is

$$
\bar{\Phi}_{1}=\tau l \bar{B}_{1}=\frac{2}{\pi} \tau l B_{1}
$$

Substituting (4) and (5) in (3) gives

$$
E_{c 1}=\frac{\pi}{\sqrt{2}} \bar{\Phi}_{1} f_{1}
$$

From the last relation, it can be seen that the flux per pole is no longer affected by the main dimensions of the machine. It can be found easily and accurately from a single measurement of the induced voltage if the rotational speed of the machine is kept constant. The same relation holds for the high order harmonic expect for the change in the signal frequency

$$
E_{c k}=\frac{\pi}{\sqrt{2}} \bar{\Phi} k f_{k}=\sqrt{2} \tau l B_{m k} f_{1}
$$

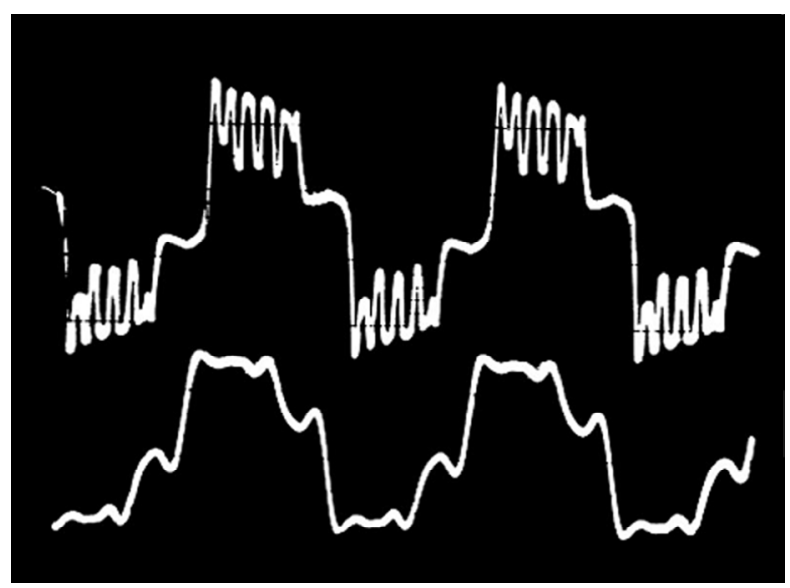

Figure 3: Measured air gap magnetic flux density

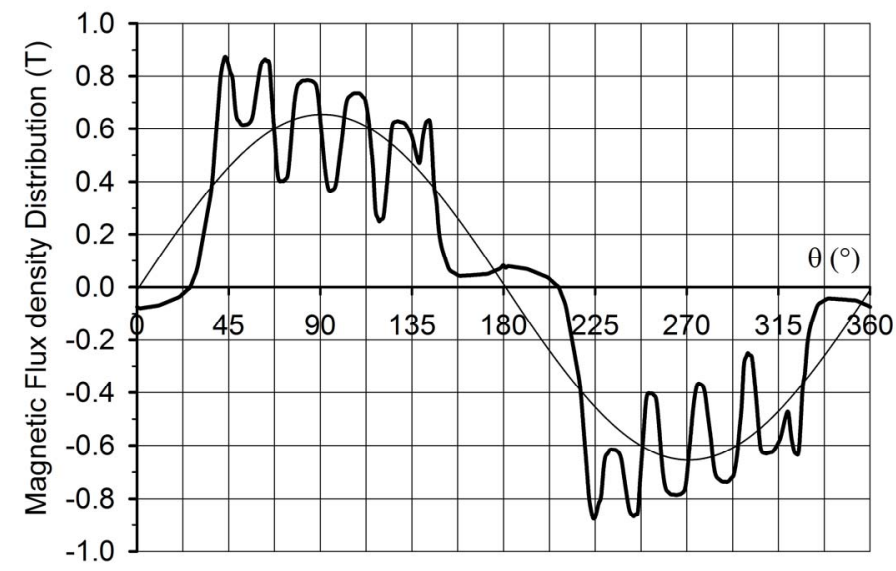

Figure 4: Measured air gap magnetic flux density obtained from digitizing signal of figure 3 . 


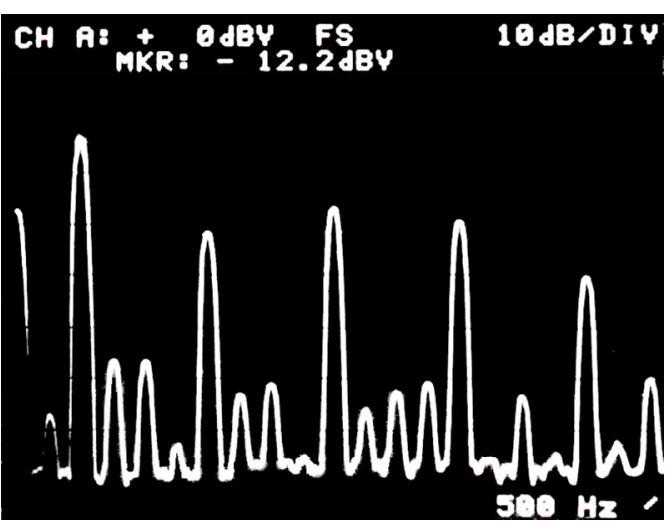

Figure 5: Measured amplitude spectrum of the air gap magnetic flux density using a search coil at no load

\section{DESCRIPTION OF THE MEASUREMENT PROCEDURE}

Two methods have been used to analyse the harmonic content of the air gap FDD; the first is based on the harmonic analysis of the induced emf in a search coil whereas the second relies on the analysis of the induced voltage in the stator windings. The experimental harmonic analysis is carried as follow. First, the measured signal, after level adjustment, is fed to a spectrum analyser, the frequency band is selected and a specific harmonic is singled out using a marker. The marker is a luminous spot which can be moved on the amplitude spectrum of the signal displayed on the screen of the spectrum analyser. The amplitude, expressed in $d B$ and the frequency of the selected harmonic are directly displayed on the screen. The measurement procedure is then repeated for each relevant harmonic. A great accuracy can be achieved by this method since the measurement procedure depends only on the frequency that is incidentally checked in permanence by the spectrum analyser.

\section{HARMONIC ANALYSIS OF THE AIR GAP FLUX}

Figure 5 shows the harmonic spectrum of the flux density waveform shown in figure 4 . It can be seen that the flux density waveforms are heavily polluted by the high order spatial harmonics and an unexpected $25 \mathrm{~Hz}$ fundamental and its multiples have been found in the amplitude spectrum, even though the machine has been run for 50 $\mathrm{Hz}$ operation. These harmonics are due to a slight asymmetry between the consecutive pair poles. Their amplitudes are relatively small, but they still affect the accuracy of the measurements. In order to appreciate the accuracy of the previous measurement method, another method has been used to extract the same information from the induced line voltage in the stator windings

\section{HARMONIC ANALYSIS THE STATOR VOLTAGES}

The second method, basically similar to the previous, relies on the harmonic analysis of the induced voltage signals in the stator winding whose waveforms are shown in figures 6 and 7. In this method, the stator winding behaves in the same times as a multipoint sensing device distributed uniformly along the air gap giving a snapshot of the whole air gap field, a selective filter owing to the distribution factors associated with each harmonics and the phase winding connection and finally as a summing device because of the series connection of the coil turns within a phase winding.

Due to the particularities of this sensing method, some harmonics actually present in the search coil signal will not be retrieved in the terminal voltage waveform as it can be seen from the comparison of pictures of figure 5 and figure 8 .

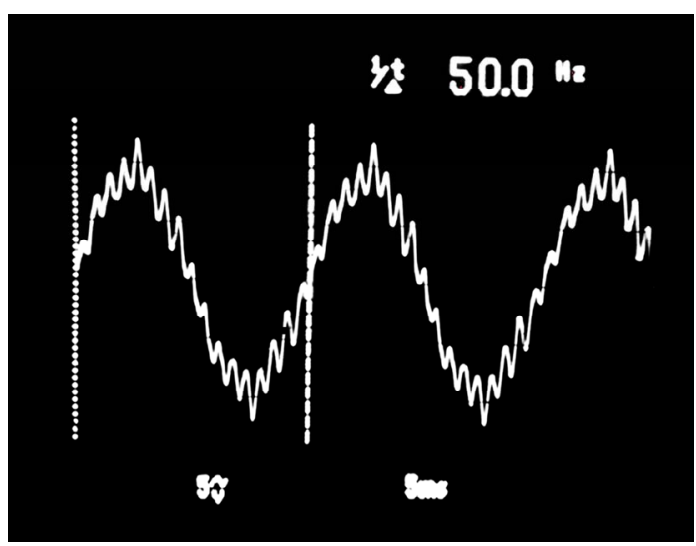

Figure 6: Actual line voltage waveform.

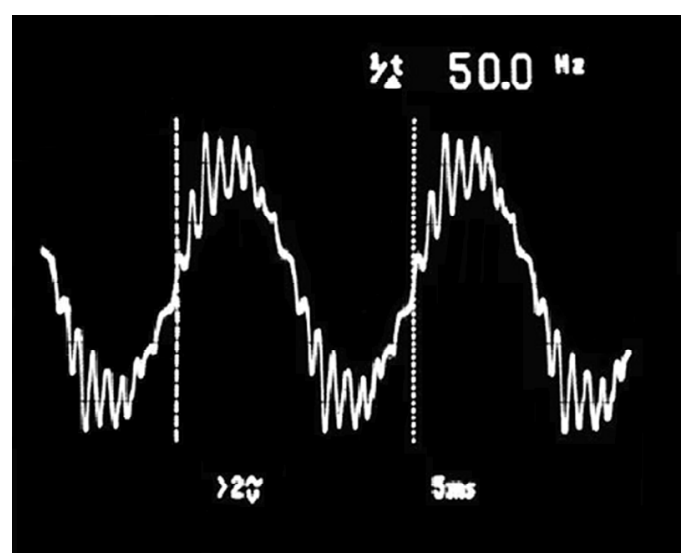

Figure 7: Actual phase voltage waveform. 
Flux per pole harmonics calculation is carried according to

$$
E_{p k}=2\left[\frac{\pi}{\sqrt{2}} \bar{\Phi}_{k} f_{k}\right] N_{c} K_{d k}
$$

Examination of relation (8) shows that the bracketed part represents the $\mathrm{r} \mathrm{m} \mathrm{s}$ value of the induced emf in the search coil. Since $N_{c}$ and $K_{d k}$ are well defined, the consistency of the experimental results may be assessed by evaluating the ratio

$$
\frac{E_{p k}}{E_{c k}}=2 N_{c} K_{d k}
$$

The amplitude phase voltage and the corresponding flux density spectrum $[1,4]$ are related to each other by

$$
E_{p k}=2 \sqrt{2} \tau l B_{m k} f_{1} K_{d k}
$$

Figures 4 shows the flux density amplitude spectrum extracted from the line voltage signals depicted in figure 3. From the line voltage waveform, it is apparent that the inherent filtering property of stator windings is not fully effective since high order harmonics are still surimposed to the line voltage fundamental.

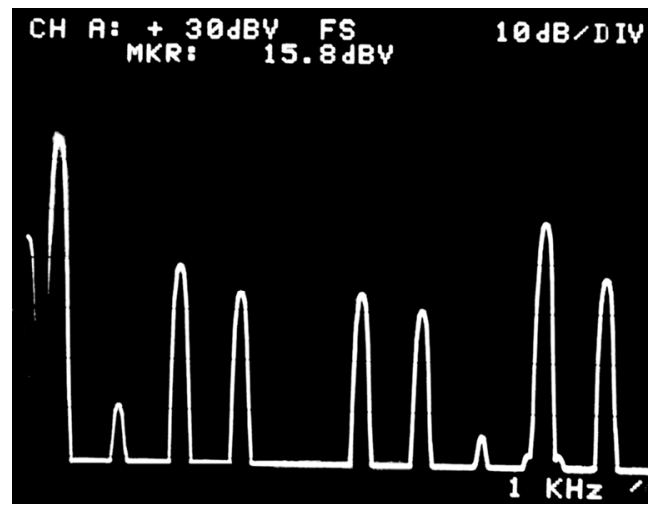

Figure 8: Measured amplitude spectrum from the line voltage at no load

However, compared to the phase voltage shown in figure 7 , the line voltage signal exhibits a great improvement in terms of high order harmonics elimination. Line voltage waveform improvement is due to 3rd order harmonic components removal by the wye connection of the stator windings. Besides their own relatively small amplitudes, they are further attenuated because of their low associated distribution factors. The $25 \mathrm{~Hz}$ sub harmonics, only present the search coil signal as shown in pictures of figure 5, are similarly removed from the line voltage signal for two main reasons. First, their amplitude is negligible and their associated distribution factors are only significant at much higher frequencies at which they become equal to that of the $50 \mathrm{~Hz}$ fundamental frequency. The more pronounced harmonics, which persist in the air gap field, the phase and the line voltage, are the tooth ripples [4]. The frequency of the tooth ripples are related to the number of slots per phase per double pole pitch $2 Q$ and their order can be found from

$$
v=2 Q k \pm 1, k \in N^{*}
$$

Bearing in mind that the number of slots per pole of the machine is 9 , the first two slot harmonics are the $17^{\text {th }}$ and $19^{\text {th }}$. Despite their high frequency, they are not eliminated from the phase and line voltage waveform signal because their distribution factors are equal to that of the fundamental. These harmonics can be only processed selectively either by chording the stator winding or skewing the stator slots, their presence in the air gap field and induced line voltage waveforms is inevitable

\section{SIGNAL RECONSTRUCTION}

To assess completely the accuracy of the measurement methods, a program has been developed to regenerate the stator voltages from the computed and measured air gap field distribution. For this purpose, a program has been devised to derive the stator winding voltages from the discrete harmonic analysis of the computed and measured magnetic flux density distribution shown respectively in figure 2 and 4 . Therefore, the accuracy of the measurement procedures exposed above can be readily assessed from the comparison the measured and computed phase and line voltage waveforms. This step provides only qualitative estimation. As far as signal waveform is concerned, it can be seen that the computed waveforms agree closely with the measured ones.

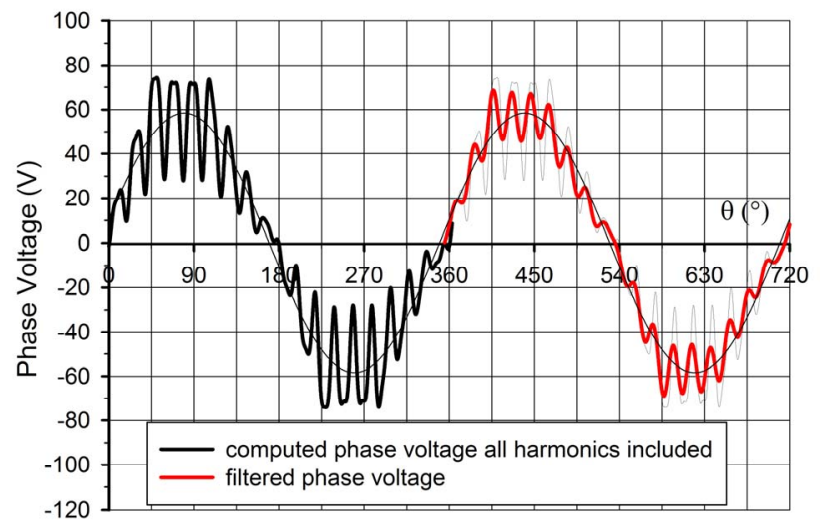

Figure 9: Computed phase voltage waveform. 


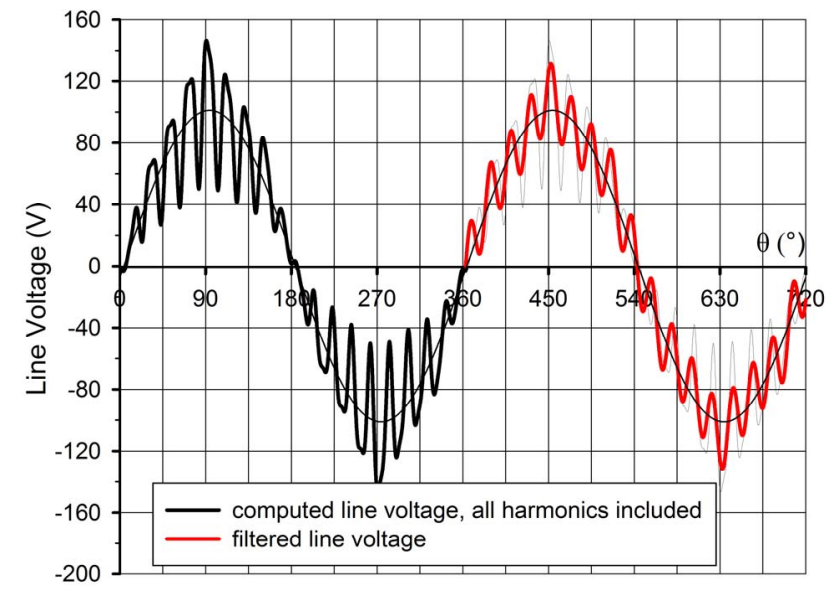

Figure 10: Computed line voltage waveform.

Finally, the accuracy of the finite element solution, in terms of harmonic content, is performed by comparing the measured and computed line voltages derived from their respective magnetic flux density distribution. Figure 11 is given to that purpose.

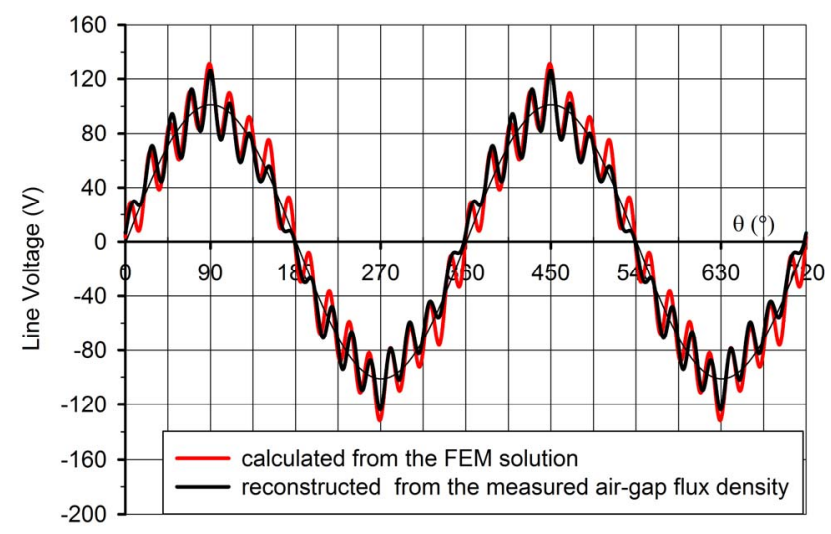

Figure 11: Comparison of the computed line voltage waveform.

The difference between the measured and computed can be accounted from many factors such the magnetic history of the actual permanent machine under scrutiny, etc. Nevertheless the last figure reveals a close agreement between the computed and measured waveforms.

The experiment has been also carried out at full load. A close agreement has been also found between the measured amplitude spectrums using both methods.

\section{CONCLUSION}

Magnetic flux density measurement is a vital aspect in the evaluation of the overall performance of a given design. In this respect, two measurement methods have been used to enable a cross comparison between the measured results and close agreement has been found.
A final check of the accuracy of the measurement procedure has been made through the comparison of the actual and simulated voltage in the stator winding. Although, this measurement procedure has been used in connection with a specific a device, it can be applied without any restriction to other machines.

\section{LIST OF SYMBOLS}

$B_{m k}$ peak value of the $\mathrm{k}^{\text {th }}$ flux density harmonic

$\Phi_{k}$ peak value of the $\mathrm{k}^{\text {th }}$ flux harmonic

$E_{c k}$ r.m.s value of the $\mathrm{k}^{\text {th }}$ induced voltage

$E_{p k}$ r.m.s value of the $\mathrm{k}^{\text {th }}$ induced phase voltage

FDD flux density distribution

$f_{1}$ fundamental frequency

$v$ pheripheral speed of the rotor

$l$ effective conductor length

$\tau$ pole pitch

$\theta$ angular position

$N_{c}$ number of conductors per phase

$Q$ number of slots per pole

$v$ teeth ripple harmonic order

\section{REFERENCES}

[1] M.G. Say, "Alternating current machines" 5th edition, Pitman Publishing Ltd, London, 1982

[2] T. Torschanoff, "Survey of numerical method in field calculation", IEEE Transactions on Magnetics, Vol. MAG. 20, N 5, pp 1912-1917, Sept. 1984

[3] J.K. SYKULSKI ,"Computational electromagnetics for design optimisation: the state of the art and conjectures for the future Bulletin of the Polish Academy of SciencesTechnical Sciences Vol. 57, No. 2, 2009 pp123-131

[4] K. B. Baltzis, "The FEMM Package: A Simple, Fast, and Accurate Open Source Electromagnetic Tool in Science and Engineering" Journal of Engineering Science and Technology Review 1 (2008), pp. 83-89.

[5] P. Zhou, W.N. Fu, D. Lin, S. Stanton, Z.J. Cendes, "Numerical modeling of magnetic evices," IEEE Trans. on Magn., Vol. 40, No. 4, pp. 1803 - 1809, July 2004.

[6] K..J. Binns, , C.P. Riley and T.M. Wong, "The efficient evaluation of torque and field gradient in permanent magnet with small air gap", IEEE Transactions on Magnetics, Vol. MAG. 21, $\mathrm{N}^{\circ} 6$, pp 2435-2438, Nov. 1985

[7] M. Kostenko and, L. Piotroski ,"Electric machines: Alternating current machines", Vol.2, Mir Publishers, Moscow, 1963 